\title{
Correlation of Vitamin D Deficiency With Severity of Chronic Heart Failure as Assessed by Functional Class and N-Terminal Pro-Brain Natriuretic Peptide Levels
}

\author{
Parminder S. Otaal ${ }^{1}$, Sudheer Pachipala ${ }^{2}$, Lipi Uppal ${ }^{1}$, Dinakar Bootla ${ }^{1}$ \\ 1. Department of Cardiology, Post Graduate Institute of Medical Education and Research, Chandigarh, IND 2. \\ Department of Medicine, Post Graduate Institute of Medical Education and Research, Chandigarh, IND
}

Corresponding author: Parminder S. Otaal, psotaal@gmail.com

\begin{abstract}
Introduction

Chronic heart failure (CHF) is a major cause of mortality and morbidity in spite of tremendous advances in medical therapies. Vitamin D deficiency has been increasingly recognised in heart failure and its therapeutic as well as prognostic implications are debated. This study was carried out to examine the relationship of Vitamin D levels with severity of heart failure as assessed by NYHA functional class and serum N-terminal pro-brain natriuretic peptide (NT-pro-BNP) levels in vitamin D deficient patients with CHF.
\end{abstract}

\section{Methodology and results}

In this cross-sectional analysis, 119 patients of symptomatic CHF presenting to the outpatient/inpatient department of cardiology in a tertiary care institute in North India were screened. Patients were categorised according to their functional class as New York Heart Association (NYHA) class II, III, IV and their serum levels of vitamin D and NT-pro-BNP were measured. Out of 119 patients, 107 (90\%) were found to have low vitamin D levels which were classified as insufficient $(20-30 \mathrm{ng} / \mathrm{ml})(\mathrm{n}=25,23 \%)$ or deficient $(<20 \mathrm{ng} / \mathrm{ml})$ $(\mathrm{n}=82,77 \%)$. The mean NT-pro-BNP levels increased significantly across functional class as $3783 \pm 6132 \mathrm{pg} / \mathrm{ml}$, $7866 \pm 4383 \mathrm{pg} / \mathrm{ml}, 21115 \pm 11905 \mathrm{pg} / \mathrm{ml}$ in NYHA class II, III and IV respectively $(\mathrm{p}=0.000)$. The respective mean serum Vitamin D3 levels of $11.6 \pm 5.8 \mathrm{ng} / \mathrm{ml}, 12.2 \pm 7.9 \mathrm{ng} / \mathrm{ml}, 14.4 \pm 8.9 \mathrm{ng} / \mathrm{ml}$ were not significantly different between classes $(\mathrm{p}=0.234$ ). We found no correlation between serum NT-pro-BNP and serum vitamin D levels in the study cohort across various NYHA classes. In multivariate regression model, after adjusting for various co-variates, vitamin D levels were not significantly associated with NT-pro-BNP or functional class in patients with CHF.

\section{Conclusion}

Patients with CHF have a high prevalence (90\%) of vitamin D deficiency. Although NT-pro-BNP levels increase significantly, vitamin D levels do not vary significantly with worsening NYHA classes. Further, no consistent significant correlation of vitamin D deficiency with NT-pro-BNP across different NYHA classes was observed. Thus, low levels of vitamin D didn't predict the severity and prognosis of patients with heart failure.

Categories: Cardiology, Family/General Practice, Internal Medicine Keywords: heart failure, severity, nt-pro bnp, vitamin-d deficiency

\section{Introduction}

With growing older population and improved overall survival, the prevalence of chronic heart failure (CHF) is increasing and currently estimated at about 37.7 million across the world [1]. Even with optimal medical management and recent therapeutic advances, the prognosis of heart failure remains dismal with $60 \%$ to $70 \%$ mortality within five years of follow-up [2]. The pathophysiological mechanisms implicated for poor outcomes include excessive neurohormonal activation, negative cardiac remodelling, persistent inflammation, fluid retention and deficiency of various macronutrients and micronutrients [3]. Vitamin D or 1,25 di-hydroxy cholecalciferol deficiency particularly seems to influence cardiovascular outcomes including myocardial infarction, stroke, peripheral vascular disease and heart failure $[4,5]$. The exact mechanism remains obscure, however in vitro studies have demonstrated its role in intracellular calcium metabolism, myocardial contractility, downregulation of renin-angiotensin-aldosterone system, prevention of excessive cardiac remodelling and suppression of inflammation $[6,7]$. Genetic disruption of the vitamin D receptor in animal studies has led to overstimulation of the renin-angiotensin system, in turn causing high blood pressure and increased concentration of biomarkers like atrial natriuretic peptide [8]. Some of the previous 
studies have shown worse prognosis with vitamin D deficiency in those with heart failure [9,10], although data of its effect on the severity of heart failure are lacking. So, we hypothesized that low vitamin D levels may contribute to the pathogenesis and severity of heart failure and can become a potential therapeutic target in such patients. Amino terminal pro-brain natriuretic peptide (NT-pro-BNP) which is an inactive derivative of prohormone pro-BNP, is a reliable marker of mortality and prognosis in heart failure [11]. It objectively assesses the severity of heart failure and is often used in therapeutic monitoring in such patients [12]. Because of its proven reliability, we used NT-Pro-BNP in addition to the functional NYHA class to objectively assess heart failure severity. We, therefore, conducted this study to examine the degree of hypovitaminosis-D in CHF and to assess any correlation with the severity of heart failure.

\section{Materials And Methods \\ Patient selection}

This is a single centre, cross-sectional study conducted by enrolling heart failure patients presenting to the outpatient section or admitted in the inpatient section of Advanced Cardiac Centre of Department of Cardiology in the Postgraduate Institute of Medical Education and Research, a tertiary care hospital in North India, from July 2016 to November 2017.

\section{Inclusion criteria}

Patients more than 18 years of age with symptoms of heart failure (New York Heart Association, NYHA class II, III and IV) for more than three months duration, left ventricular ejection fraction $<45 \%$, and serum $25(\mathrm{OH}) \mathrm{D} 3<30 \mathrm{ng} / \mathrm{ml}$ were included.

\section{Exclusion criteria}

Patients on vitamin and calcium supplements, those suffering from systemic diseases including chronic kidney disease, malignancy, sarcoidosis, gastro-intestinal malabsorption states and untreated valvular heart disease were excluded from the study.

The study conforms to the Helsinki declaration. Ethical approval was taken from the Institute's ethic thesis committee. Written informed consent was given by all patients.

\section{Biochemical investigations}

All the patients underwent baseline blood investigations including serum electrolytes, serum creatinine, complete blood counts including haemoglobin levels. Serum 25-hydroxy vitamin D3 (25(OH)D3) and Nterminal pro-brain natriuretic peptide (NT-pro-BNP) levels were measured in all the patients after overnight fasting. Vitamin D deficiency was defined as $25(\mathrm{OH}) \mathrm{D} 3$ levels $<20 \mathrm{ng} / \mathrm{mL}$, insufficiency as $20-29 \mathrm{ng} / \mathrm{mL}$ and sufficiency as $\geqslant 30 \mathrm{ng} / \mathrm{mL}[13]$.

\section{Cardiac evaluation}

The participants were classified according to New York Heart Association (NYHA) functional classification into class II, III and IV [14]. 2D echocardiography was performed in all participants by an experienced cardiologist who was blinded to patient characteristics. Left ventricular ejection fraction (LVEF) was calculated by Simpson's biplane method and left ventricular dimensions were measured in M-mode using Philips IE33/ Philips EPIQ 7 (echocardiography) system (Philips healthcare TM, Amsterdam, the Netherlands) [15].

\section{Statistical analysis}

Normally distributed parameters were presented as mean \pm standard deviation. Continuous parameters following a non-normal distribution were presented as median and interquartile range (IQR). Categorical data were given as percentages. Based on the patients' worst NYHA functional class in the last three months, three subgroups were formed, NYHA II, NYHA III and NYHA IV. Comparisons among heart failure subgroups were performed by analysis of variance (ANOVA) with P for linear trend for continuous parameters or ANOVA on ranks for nonparametric data. A chi-square test was performed for categorical variables. Simple correlation analyses (Pearson or Spearman correlations where appropriated) and multiple linear regression analyses including several independent variables were performed to examine whether vitamin $\mathrm{D}$ levels were associated with NT-pro-BNP levels. A p-value $<0.05$ was considered statistically significant. Data analysis was done using Statistical Product and Service Solutions (SPSS) 22.0 statistical package.

\section{Results}

\section{Baseline characteristics}

Baseline characteristics of the study population are shown in Table 1. 


\section{Cureus}

\begin{tabular}{|c|c|c|c|c|c|}
\hline Parameter & $\begin{array}{l}\text { NYHA II ( }= \\
\text { 39) }\end{array}$ & $\begin{array}{l}\text { NYHA III ( }= \\
\text { 29) }\end{array}$ & $\begin{array}{l}\text { NYHA IV }(n= \\
\text { 39) }\end{array}$ & $\begin{array}{l}\text { TOTAL }(n= \\
\text { 107) }\end{array}$ & $\begin{array}{l}\mathrm{p}- \\
\text { value }\end{array}$ \\
\hline Age (years) & $59.21 \pm 12.3$ & $56.62 \pm 14.66$ & $56.97 \pm 11.24$ & $57.69 \pm 12.55$ & 0.64 \\
\hline Female, n (\%) & $12(30.7)$ & $8(27.5)$ & $12(30.7)$ & 32 (29.9) & \multirow{2}{*}{0.95} \\
\hline Male, n (\%) & 27 (69.2) & 21 (72.4) & $27(69.2)$ & 75 (70.09) & \\
\hline \multicolumn{6}{|l|}{ Comorbidities } \\
\hline T2DM, n (\%) & $11(28.2)$ & $14(48.2)$ & $23(60)$ & $48(44.8)$ & 0.02 \\
\hline HTN, n (\%) & $14(35.8)$ & $16(55.1)$ & $22(56.4)$ & $52(48.5)$ & 0.137 \\
\hline CAD, n(\%) & $29(74.3)$ & $21(/ 2.4)$ & $30(7 t)$ & $80(74 . h)$ & 0.912 \\
\hline Smoker, n (\%) & $12(30.7)$ & $11(38)$ & $13(33.3)$ & $36(33.6)$ & 0.575 \\
\hline Alcohol, n (\%) & $15(38.4)$ & $14(48.2)$ & $14(35.8)$ & $43(40.1)$ & 0.567 \\
\hline BMI (kg/m²) & $26.6 \pm 3.49$ & $25.64 \pm 3.58$ & $26.82 \pm 3.81$ & $26.42 \pm 3.63$ & 0.385 \\
\hline TG (mg/dL) & $110.61 \pm 46.96$ & $108.04 \pm 31.23$ & $112.46 \pm 45.64$ & $110.59 \pm 42.4$ & 0.91 \\
\hline $\mathrm{HDL}$ (mg/dL) & $38.56 \pm 8.33$ & $31.11 \pm 9.64$ & $38.94 \pm 10.96$ & $36.68 \pm 10.21$ & 0.002 \\
\hline LDL (mg/dL) & $83.44 \pm 25.76$ & $73.69 \pm 27.66$ & $85.87 \pm 30.54$ & $81.68 \pm 28.27$ & 0.191 \\
\hline $\mathrm{TSH}(\mathrm{mU} / \mathrm{L})$ & $3.75 \pm 1.78$ & $3.156 \pm 1.48$ & $3.93 \pm 2.37$ & $3.46 \pm 1.95$ & 0.442 \\
\hline $\begin{array}{l}\text { Number of patients with previous decompensations, } n \\
\text { (\%) }\end{array}$ & 4 (10.2\%) & $5(17.2 \%)$ & $6(15.3 \%)$ & $15(14.01 \%)$ & 0.681 \\
\hline LVEF (\%) & $34.49 \pm 6.76$ & $27.45 \pm 10.21$ & $27.13 \pm 7.49$ & $29.9 \pm 8.73$ & 0.0001 \\
\hline HbA1C (\%) & $6.12 \pm 1.21$ & $6.7 \pm 2.01$ & $7.31 \pm 1.83$ & $6.71 \pm 1.74$ & 0.01 \\
\hline
\end{tabular}

\section{TABLE 1: Baseline characteristics of the study population according to NYHA class.}

T2DM: type 2 diabetes mellitus; HTN: hypertension; CAD: coronary artery disease; BMI: body mass index; TG: triglyceride; HDL: high-density lipoprotein; LDL: low-density lipoprotein; TSH: thyroid-stimulating hormone; LVEF: left ventricular ejection fraction; Hb1Ac: glycosylated hemoglobin; NYHA: New York Heart Association.

Out of a total of 119 patients with CHF screened, 12 had normal 25(OH) vitamin D3 levels and were excluded from the study. Rest 107 (90\%) patients were categorised according to NYHA classification as NYHA II $(\mathrm{n}=39)$, III $(\mathrm{n}=29)$ and IV $(\mathrm{n}=39)$. The mean age was $57.69 \pm 12.55$ years with males comprising $70 \%$ of the total study population. The prevalence of risk factors included type 2 diabetes mellitus in 48 patients (44.8\%), hypertension in 52 patients (48.5\%), history of smoking in 36 patients (33.6\%), history of alcohol abuse in 43 patients $(40.1 \%)$. Eighty out of $107(74.7 \%)$ patients had a history of coronary artery disease. There was no difference in the prevalence of individual risk factors among the three groups except type 2 diabetes which was more commonly seen in class IV ( $\mathrm{p}=0.02$ ). Mean LVEF was $34.49 \pm 6.76 \%, 27.451 \pm 0.21 \%$ and $27.13 \pm 7.49 \%$, respectively, in class II, class III and class IV, respectively $(\mathrm{p}=0.001)$.

Serum 25(OH)D3, NT-pro-BNP levels and NYHA class: Of 107 patients included in the study, 82 patients (76.63\%) had 25(OH) D3 deficiency $(<20 \mathrm{ng} / \mathrm{ml})$ and 25 patients (23.36\%) had 25(OH) D3 insufficiency (20-30 $\mathrm{ng} / \mathrm{ml}$ ) with mean levels of $11.6 \pm 5.8,12.2 \pm 7.9,14.4 \pm 8.9 \mathrm{ng} / \mathrm{ml}$ in class II, III and IV, respectively (Figure 1, panel A). Overall, these levels were not significantly different among the three groups $(\mathrm{p}=0.234)$. However, NT-pro-BNP levels increased significantly with $3783.34 \pm 6132.36 \mathrm{pg} / \mathrm{ml}, 7866 \pm 4383.3 \mathrm{pg} / \mathrm{ml}$ and $20670.31 \pm 12072.28 \mathrm{pg} / \mathrm{ml}$ in class II, III and IV with $\mathrm{p}<0.001$ (Figure 1, panel B). So, although increasing NTpro-BNP levels have a significant correlation with worsening NYHA class, vitamin D levels don't. 


\section{Cureus}
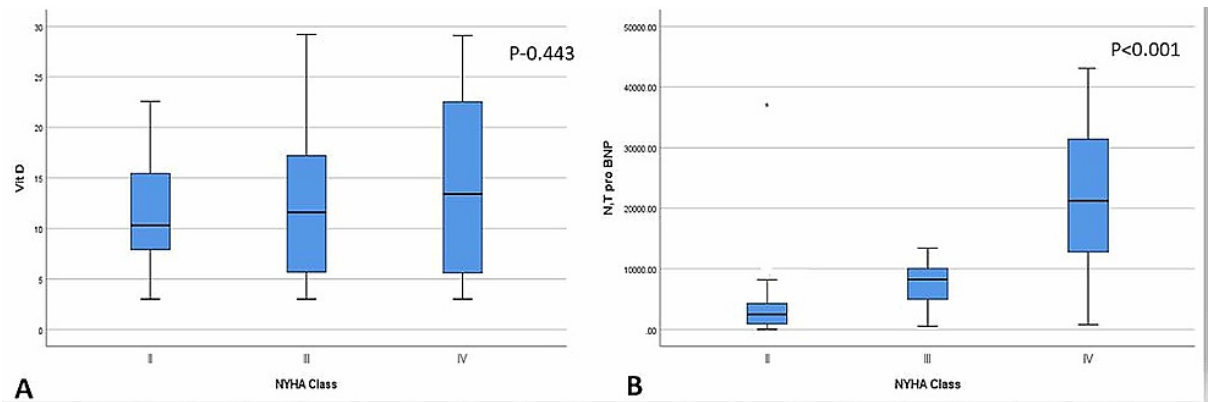

FIGURE 1: Vitamin D levels (panel A) and NT-pro-BNP levels (panel B) in NYHA class II, III and IV of chronic heart failure.

NYHA: New York Heart Association Class; Vit D: Vitamin D level; NT-pro-BNP: N-terminal pro-brain natriuretic peptide.

Correlation of vitamin D levels with NT-pro-BNP: No significant correlation was observed between serum NT pro BNP and serum vitamin D levels in the overall study cohort or among most classes of heart failure. However, among patients with NYHA class II, an inverse significant correlation was seen with $\mathrm{r}=-0.323$, $\mathrm{p}=0.045$, meaning thereby that low levels of vitamin D were associated with significantly higher NT-pro-BNP levels (Figure 2). NT-pro-BNP levels did not vary among patients with severe vitamin D deficiency $(<15 \mathrm{ng} / \mathrm{ml})$ when compared to those with higher levels $(15-30 \mathrm{ng} / \mathrm{ml})[9172.5 \pm 10080 \mathrm{pg} / \mathrm{ml}$ vs $12685 \pm 13133 \mathrm{pg} / \mathrm{ml} ; \mathrm{p}=0.174]$. In the multivariable regression model, after adjustment for various univariates, no significant correlation was observed ( $B=-41.386$ 95\% CI -262-179; $p=0.711$ ).

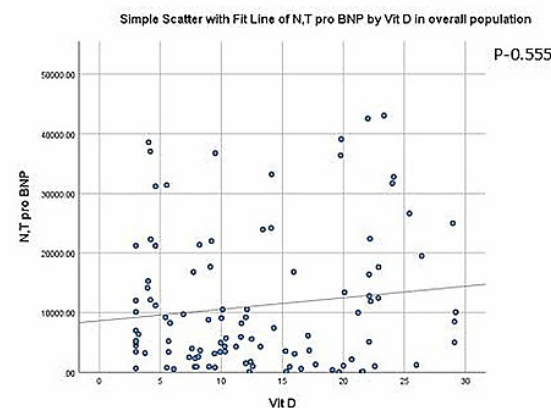

A

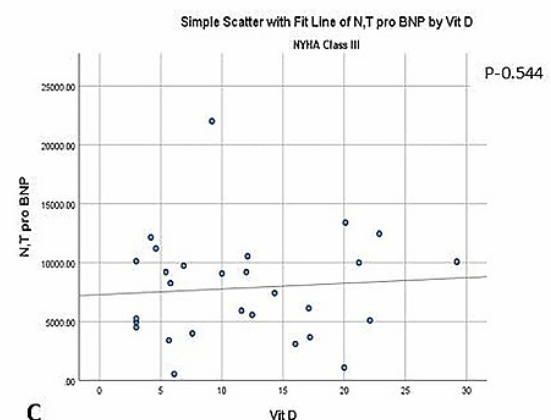

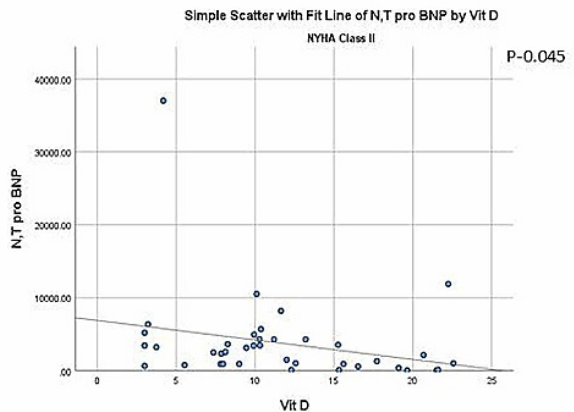

B

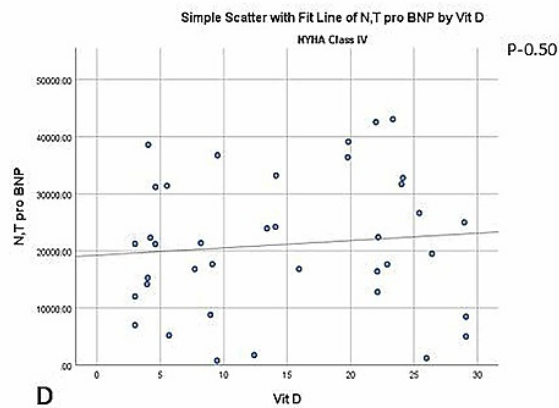

FIGURE 2: The correlation of NT-pro-BNP levels with vitamin D levels in the overall study cohort (panel A) and in patients in NYHA class II (panel B), III (panel C) and IV (panel D).

NT-pro-BNP: N-terminal pro-brain natriuretic peptide; NYHA: New York Heart Association. 


\section{Discussion}

Numerous longitudinal and cross-sectional studies have emphasized the importance of low vitamin D levels in population to predict the risk of cardiovascular disease and outcomes $[4,5,9,10,16]$. Initial populationbased studies like National Health and Nutritional Examination Survey (2001-2004) provided the evidence of hypovitaminosis (serum vitamin D3 levels $<30 \mathrm{ng} / \mathrm{ml}$ ) in $74 \%$ of the enrolled candidates with cardiovascular diseases including coronary artery disease, heart failure, and peripheral artery disease [17]. Similar findings were mirrored in the Framingham offspring study where individuals with 25(OH)D3 levels < $37.5 \mathrm{mmol} / \mathrm{L}$ had a hazard ratio of 1.62 for the development of cardiovascular diseases compared to individuals with levels $>37.5 \mathrm{mmol} / \mathrm{L}$ [5]. Interestingly, few other studies have noted an increased incidence of cardiovascular events during winter months, a finding which correlates with low vitamin D levels owing to reduced sun exposure [18].

In the setting of heart failure, some authors [19-21] have described the increased prevalence of vitamin D deficiency. However, its relationship with severity and causality remains unknown. Alsafwah et al. reported a very high prevalence of vitamin D deficiency in those with heart failure (95\%) than in the normal population (33\%); however, no difference was observed between compensated and decompensated heart failure patients [19]. In a large study comprising of 23,793 vitamin D deficient patients from the Intermountain Health care system, the hazard ratio for development of heart failure in patients with very low vitamin D (<15 ng/ml ) was 2.01 vs 1.31 in patient with low vitamin D levels (16-30ng/ml) [16]. The increased incidence and prevalence of heart failure in patients with vitamin $\mathrm{D}$ deficiency points towards its protective effects via various local or systemic mechanisms and thus has been explored further [22].

Our study found a very high prevalence ( $90 \%$ of those screened) of vitamin D deficiency or insufficiency in those with CHF. Indians are known to have vitamin D deficiency in general population ranging from $50 \%$ to 94\% and the causes include poor dietary intake, inadequate sunlight exposure and increased skin pigmentation [23]. Additionally, in patients with heart failure inadequate gastrointestinal absorption, decreased mobility and persistent catabolic state may further contribute. Nonetheless, even after adjustments for physical limitation, studies evaluating the cardiovascular outcomes in CHF have reported poor prognosis in patients having vitamin D deficiency [9].

The present study further evaluated the prognostic role of vitamin D levels and its correlation with serum NT-pro-BNP levels in patients with CHF. Although vitamin D levels were insufficient or deficient in $90 \%$ of patients, it had no significant correlation with clinical severity of heart failure or NT-pro-BNP levels. Although NT-pro-BNP in our study progressively increased with mean serum levels of 3783.34 6132.36 , $7866 \pm 4383.3$ and $20670.31 \pm 12072.28 \mathrm{pg} / \mathrm{ml}$ in patients in NYHA class II, III and IV, respectively $(\mathrm{p}<0.001)$, no significant trend was observed in vitamin D levels. Additionally, NT-pro-BNP levels did not differ among patients with severe vitamin D deficiency $(<15 \mathrm{ng} / \mathrm{dl})$ vs those with low to moderately low levels $(15-30 \mathrm{ng} / \mathrm{ml})$ $[9172.5 \pm 10080 \mathrm{pg} / \mathrm{ml}$ vs $12685 \pm 13133 \mathrm{pg} / \mathrm{ml} ; \mathrm{p}=0.174]$.

Other studies examining the effects of severe vitamin D deficiency and its supplementation have reported contradictory findings. Our results are supported by a randomised controlled trial by Seirafian et al. in which in spite of adequately replacing vitamin $\mathrm{D}$ in dialysis-dependent renal failure patients, there was no significant difference in serum pro-BNP, iPTH, calcium, phosphorus or albumin levels after 12 weeks between study groups [24]. Another study by Schleithoff et al. reported improvement in cytokine profile including TNF alpha and Interleukin 10; however, no change was noted in the NT-pro-BNP levels or clinical outcome in those who received vitamin D supplementation [25]. Some other authors also did not find any correlation between NT-pro-BNP and vitamin D levels in patients with congenital heart disease or myocardial infarction $[25,26]$.

A few observational studies, like the one by Liu et al. described an association between low vitamin D levels and activated renin-angiotensin system and proinflammatory state. The study found increased plasma renin activity and higher levels of $\mathrm{C}$ reactive protein and TNF alpha in those with low vitamin D levels. They also noted a numerically increasing rate of hospitalisations, across decreasing $25(\mathrm{OH})$ tertiles [10]. Similarly, in an observational study by Schierbeck et al. in a population of 148 heart failure patients with reduced ejection fraction, low levels of vitamin D and secondary hyperparathyroidism were associated with increased mortality during 3.5 years of follow-up. Moreover, NT-pro-BNP levels increased significantly with increasing PTH tertiles [27]. Thus most randomised controlled trials have been unable to conclusively define the role of vitamin D in patients with heart failure [28]. VINDICATE study suggested that vitamin D might offer cardio protection as it found an increase of $6 \%$ in LVEF after supplementing with 4,000 IU of vitamin D daily for six months. Despite this, it did not find any difference in $6 \mathrm{~min}$ walk test (the primary endpoint) or in NT-proBNP levels [29].

Our study presents another piece of evidence supporting no correlation of serum vitamin D levels with severity of heart failure as measured by NYHA classification and serum NT-pro-BNP levels, in the Indian population. A recent metanalysis also reached a similar conclusion that vitamin D supplementation has a small effect on circulating inflammatory markers but no improvement in serum NT-pro-BNP levels or left ventricular ejection fraction [30]. 
Just like its ambiguity as a marker of poor prognosis, vitamin D continues to suffer from the lack of evidence demonstrating its protective effects and therapeutic potential. In the present analysis in patients of chronic heart failure with reduced ejection fraction, severity of vitamin D deficiency did not influence functional severity and is unlikely to affect prognosis.

However, the present study has several limitations. We didn't measure serum calcium and serum parathormone levels. We understand that vitamin D deficiency leads to low calcium and secondary hyperparathyroidism which is known to influence heart failure outcomes. Moreover, only heart failure patients with reduced ejection fraction were included in our study and results cannot be extrapolated to those patients presenting with heart failure with preserved ejection fraction. Additionally, as the sample size is small, a larger study is needed to validate our findings.

\section{Conclusions}

Patients with CHF were found to have a high prevalence of vitamin D deficiency. Worsening of levels of vitamin D deficiency were not associated with increasing severity of CHF as measured by NT-pro-BNP or functional NYHA class in patients with reduced ejection fraction. Further low levels of vitamin D were not associated with prognosis of heart failure.

\section{Additional Information \\ Disclosures}

Human subjects: Consent was obtained or waived by all participants in this study. Institutional Thesis Committee issued approval Endst.no.10603/PG-2Trg/2015/2249-50. The research study was approved by Thesis Committee of Post Graduate Institute of Medical Education and Research, Chandigarh, India . Animal subjects: All authors have confirmed that this study did not involve animal subjects or tissue. Conflicts of interest: In compliance with the ICMJE uniform disclosure form, all authors declare the following: Payment/services info: All authors have declared that no financial support was received from any organization for the submitted work. Financial relationships: All authors have declared that they have no financial relationships at present or within the previous three years with any organizations that might have an interest in the submitted work. Other relationships: All authors have declared that there are no other relationships or activities that could appear to have influenced the submitted work.

\section{References}

1. Ziaeian B, Fonarow GC: Epidemiology and aetiology of heart failure. Nat Rev Cardiol. 2016, 13:368-378. 10.1038/nrcardio.2016.25

2. Shah KS, Xu H, Matsouaka RA, et al.: Heart failure with preserved, borderline, and reduced ejection fraction: 5-year outcomes. J Am Coll Cardiol. 2017, 70:2476-2486. 10.1016/j.jacc.2017.08.074

3. Kemp CD, Conte JV: The pathophysiology of heart failure. Cardiovasc Pathol. 2012, 21:365-371. 10.1016/j.carpath.2011.11.007

4. Kendrick J, Targher G, Smits G, Chonchol M: 25-Hydroxyvitamin D deficiency is independently associated with cardiovascular disease in the Third National Health and Nutrition Examination Survey. Atherosclerosis. 2009, 205:255-260.10.1016/j.atherosclerosis.2008.10.033

5. Wang TJ, Pencina MJ, Booth SL, et al.: Vitamin D deficiency and risk of cardiovascular disease . Circulation. 2008, 117:503-511. 10.1161/CIRCULATIONAHA.107.706127

6. Li YC, Kong J, Wei M, Chen ZF, Liu SQ, Cao LP: 1,25-Dihydroxyvitamin D(3) is a negative endocrine regulator of the renin-angiotensin system. J Clin Invest. 2002, 110:229-238. 10.1172/JCI15219

7. Inanir A, Ozoran K, Tutkak H, Mermerci B: The effects of calcitriol therapy on serum interleukin-1, interleukin- 6 and tumour necrosis factor-alpha concen- trations in post-menopausal patients with osteoporosis. J Int Med Res. 2004, 32:570-582. 10.1177/147323000403200602

8. Xiang W, Kong J, Chen S, et al.: Cardiac hypertrophy in vitamin D receptor knockout mice: role of the systemic and cardiac renin-angiotensin systems. Am J Physiol Endocrinol Metab. 2005, 288:e125-e132. 10.1152/ajpendo.00224.2004

9. Pilz S, März W, Wellnitz B, et al.: Association of vitamin D deficiency with heart failure and sudden cardiac death in a large cross-sectional study of patients referred for coronary angiography. J Clin Endocrinol Metab. 2008, 93:3927-3935. 10.1210/jc.2008-0784

10. Liu LC, Voors AA, Veldhuisen DJ, et al.: Vitamin D status and outcomes in heart failure patients . Eur J Heart Fail. 2011, 13:619-625. 10.1093/eurjhf/hfr032

11. Bettencourt P, Azevedo A, Pimenta J, Friões F, Ferreira S, Ferreira A: N-terminal-pro-brain natriuretic peptide predicts outcome after hospital discharge in heart failure patients. Circulation. 2004, 110:21682174. 10.1161/01.CIR.0000144310.04433.BE

12. Latini R, Masson S.: NT-proBNP: NT-proBNP: a guide to improve the management of patients with heart failure. EJIFCC. 2013, 24:78-84.

13. Kuriacose R, Olive KE: Prevalence of vitamin D deficiency and insufficiency in northeast Tennessee . South Med J. 2008 Sep, 101:906-909. 10.1097/SMJ.0b013e318181881b

14. Bennett JA, Riegel B, Bittner V, Nichols J: Validity and reliability of the NYHA classes for measuring research outcomes in patients with cardiac disease. Heart \& Lung. 2002, 31:262-270. $10.1067 / \mathrm{mhl} .2002 .124554$

15. Lang RM, Badano LP, Mor-Avi V, et al.: Recommendations for cardiac chamber quantification by echocardiography in adults: an update from the American Society of Echocardiography and the European 
Association of Cardiovascular Imaging. J Am Soc Echocardiogr. 2015, 28:1-39. 10.1016/j.echo.2014.10.003

16. Anderson JL, May HT, Horne BD, et al.: Relation of vitamin D deficiency to cardiovascular risk factors, disease status, and incident events in a general healthcare population. Am J Cardiol. 2010, 106:963-968. 10.1016/j.amjcard.2010.05.027

17. Kim DH, Sabour S, Sagar UN, Adams S, Whellan DJ: Prevalence of hypovitaminosis D in cardiovascular diseases (from the National Health and Nutrition Examination Survey 2001 to 2004). Am J Cardiol. 2008, 102:1540-1544. 10.1016/j.amjcard.2008.06.067

18. Fares A: Winter cardiovascular diseases phenomenon. North Am J Med Sci. 2013, 5:266-279. 10.4103/19472714.110430

19. Alsafwah S, Laguardia SP, Nelson MD, Battin DL, Newman KP, Carbone LD, Weber KT: Hypovitaminosis D in African Americans residing in Memphis, Tennessee with and without heart failure. Am J Med Sci. 2008, 335:292-297. 10.1097/maj.0b013e318167b0bd

20. Zittermann A, Schleithoff SS, Tenderich G, Berthold HK, Körfer R, Stehle P: Low vitamin D status: a contributing factor in the pathogenesis of congestive heart failure?. J Am Coll Cardiol. 2003, 41:105-112. 10.1016/s0735-1097(02)02624-4

21. Lutsey PL, Michos ED, Misialek JR, et al.: Race and vitamin D binding protein gene polymorphisms modify the association of 25-hydroxyvitamin D and incident heart failure: The ARIC (Atherosclerosis Risk in Communities) Study. JACC Heart Fail. 2015 May, 3:347-356. 10.1016/j.jchf.2014.11.013

22. Reddy Vanga S, Good M, Howard PA, Vacek JL: Role of vitamin D in cardiovascular health . Am J Cardiol. 2010, 106:798-805. 10.1016/j.amjcard.2010.04.042

23. Aparna P, Muthathal S, Nongkynrih B, Gupta SK: Vitamin D deficiency in India . J Family Med Prim Care. 2018, 7:324-330. 10.4103/jfmpc.jfmpc_78_18

24. Seirafian S, Haghdarsaheli Y, Mortazavi M, Hosseini M, Moeinzadeh F: The effect of oral vitamin D on serum level of N-terminal pro-B-type natriuretic peptide. Adv Biomed Res. 2014, 3:261. 10.4103/2277-9175.148234

25. Schleithoff SS, Zittermann A, Tenderich G, Berthold HK, Stehle P, Koerfer R: Vitamin D supplementation improves cytokine profiles in patients with congestive heart failure: a double-blind, randomized, placebocontrolled trial. Am J Clin Nutr. 2006, 83:754-759. 10.1093/ajcn/83.4.754

26. Passeri E, Rigolini R, Costa E, Verdelli C, Arcidiacono C, Carminati M, Corbetta S: Serum NT-proBNP levels are not related to vitamin D status in young patients with congenital heart defects. Dis Markers. 2016, 2016:3970284. 10.1155/2016/3970284

27. Schierbeck LL, Jensen TS, Bang U, Jensen G, Køber L, Jensen JE: Parathyroid hormone and vitamin Dmarkers for cardiovascular and all cause mortality in heart failure. Eur J Heart Fail. 2011, 13:626-632. 10.1093/eurjhf/hfr016

28. Zittermann A, Ernst JB, Prokop S, et al.: Effect of vitamin D on all-cause mortality in heart failure - a 3-year randomized clinical trial with 4000 IU of vitamin D daily. Eur Heart J. 2017, 38:2279-2286. 10.1093/eurheartj/ehx235

29. Witte KK, Byrom R, Gierula J, et al.: Effects of vitamin D on cardiac function in patients with chronic HF: the VINDICATE study. J Am Coll Cardiol. 2016, 67:2593-2603. 10.1016/j.jacc.2016.03.508

30. Rodriguez AJ, Mousa A, Ebeling PR, Scott D, de Courten B: Effects of vitamin D supplementation on inflammatory markers in heart failure: a systematic review and meta-analysis of randomized controlled trials. Sci Rep. 2018, 8:1169. 10.1038/s41598-018-19708-0 